\title{
Fenomenología de la otredad y su importancia en los cambios de conversación sobre ética, límite y moral
}

\section{Phenomenology of otherness and its importance in conversational changes about ethics, limits and morals}

\author{
Jinette Labrador \\ inettelabrador@gmail.com \\ Universidad del Zulia \\ Venezuela \\ https://orcid.org/0000-0002-9475-6524 \\ Gabriel Argota \\ gabrielargota@hotmail.com \\ Instituto Indígena de Aremasain \\ Colombia \\ https://orcid.org/0000-0002-1933-9966 \\ Juana Ojeda \\ juanacecilia@hotmail.com \\ Universidad del Zulia \\ Venezuela \\ https://orcid.org/0000-0001-6908-3252
}

Recibido: 15 de abril de 2019

Aprobado: 20 de mayo de 2019

\section{RESUMEN}

La otredad explica cómo es que las personas hacen lo que hacen, bien desde una actitud de respeto, como de negación al otro, esto último reflejado en conductas disruptivas que conllevan a conflictos interpersonales ante la diversidad de pensamiento, específicamente en el gremio docente. Razón por la que, el presente estudio tuvo como objetivo comprender la dinámica interna de la otredad en educadores del Internado Indígena San Antonio de Aremasain de Colombia. La metodología que direccionó la investigación se basó en el fenomenológico, por cuanto, los actores sociales involucrados exploraron, describieron y comprendieron de las experiencias narradas los elementos en común de tales vivencias. Se pudo concluir que al cambiar las distinciones y por ende la red de conversaciones, hay un cambio en los sentires, haceres y emociones de las personas.

Descriptores: Otredad; Ética; Límite; Moral; Conversaciones. 


\section{SUMMARY}

The otherness explains how people do what they do, either from an attitude of respect, as from denial to the other, the latter reflected in disruptive behaviors that lead to interpersonal conflicts in the face of diversity of thought, specifically in the teaching guild. This is why this study aimed to understand the internal dynamics of otherness in educators of the Indigenous Intern San Antonio de Aremasain of Colombia. The methodology that directed the research was based on phenomenological, as the social actors involved explored, described and understood from the narrated experiences the common elements of such experiences. It was concluded that by changing the distinctions and therefore the network of conversations, there is a change in people's feelings, doing, and emotions.

Descriptors: Otherness; Ethics; Limit; Moral; Conversations.

\section{INTRODUCCIÓN}

Un modo común de definir la ética es la que se refiere al "conjunto de normas morales que rigen la conducta de las personas en cualquier ámbito de la vida" (DLE, 2014); el significado de límite se articula más como "extremo que pueden alcanzar lo físico y lo anímico" (DLE, 2014) y a la moral se le ha otorgado lo "perteneciente o relativo a las acciones de las personas, desde el punto de vista de su obrar en relación con el bien o el mal y en función de su vida individual y, sobre todo colectiva" (DLE, 2014). Ante estas concepciones, se evidencia que el hombre en su evolución buscó-y busca- la manera de organizar la vida "creando micro-mundos que utiliza como esquemas de intervención hacia sí mismo y hacia los demás, configurando su identidad que le permite ser-en-el mundo" (Varela, 1996, p. 16). Esto es, el hombre como ser relacional opera mediantes las distinciones, gustos, intereses, etc. que configura en los cambios ontogénicos y filogenéticos a lo largo de su presente, que es cambiante continúo.

Es decir, aunque la persona tiene momentos de soledad y silencio, la vida humana se desarrolla en una dimensión con y entre seres vivos; en tal sentido, la otredad es un término que va más allá de decir es la aceptación del otro, la otra, lo otro; el término otredad implica cómo se llega a aceptar al otro como un legítimo aun cuando no se compartan los mismos intereses, deseos, gustos, cuando se difiera en las ideologías, implica cómo se llega al mutuo respeto y, con ello, a moverse desde la emoción del 
amor, sin que ésta esté presente sólo en el núcleo familiar, universitario o comunitario (vecindad).

Por tanto, connota una dinámica, porque el ser vivo humano es un sistema, una totalidad, bajo la forma de arquitecturas dinámicas que escriben y son protagonistas de su propia biografía. También connota un proceso reflexivo-crítico-autónomo y de acción, donde se develan los sentires íntimos, las emociones, haceres y conversaciones del ser vivo humano que sustentan o conservan las acciones que pueden ocasionar en la persona o en quienes le rodean estados de bien-estar o de mal-estar, en las que se pueden mover él o ella misma. De modo que, la otredad para Labrador (2018) es:

El proceso de reflexión autoconsciente de la propia naturaleza humana, que devela los sentires íntimos, haceres y emociones en el ámbito sensorial-operacional-relacional con el otro, la otra, lo otro, donde en la dinámica relacional organismo-nicho en el ocurrir del presente cambiante continuo de las configuraciones generales, se hacen las abstracciones que la operación del distinguir trae un mundo a la mano. (p.55)

Encontrarse los docentes del Internando Indígena San Antonio de Aremasain de Riohacha en la experiencia de la disertación de la otredad y la importancia que tiene en las redes de conversaciones que manejan sobre ética, moral y límite, permitió configurar lo que Santana (2000) distingue como eticidad (valores comunes) y moralidad de forma intuitiva, considerando los requisitos sociales, religiosos y culturales que fueron concientizando cómo se dan las relaciones entre ellos, si son colaborativas y no colaborativas.

Lo señalado en el anterior párrafo se llevó a cabo debido a que se percibió la influencia de una tendencia globalizadora, la cual para Santana (2000), "es la implantación de la doctrina neoliberal, que ha conducido a la formación de mercados monopolizados dominados por oligopolios" cuyo lema es la competencia. Ésta representada en un sistema de comunicación de liderazgo jerárquico, no-ético: coordinación de personas considerando lo autoritario, deseo de control en un fluir de sentires y emociones caracterizados por falta al auto-respeto, relaciones de poder y sometimiento 
(Autoridad y obediencia), proyectos impuestos, conversaciones basados en quejas, plasticidad conductual (la persona desaparece reduciéndose su inteligencia).

Razón por la que se emprendió el estudio con el fin o el objetivo de comprender la dinámica interna de la otredad en educadores del Internado Indígena San Antonio de Aremasain de Colombia, mediante el proceso autoconsciente, considerando la ética, el límite y la moral, para cambiar las redes de conversaciones y las distinciones que generen en los sentires, haceres y emociones relaciones colaborativas.

\section{Configuraciones senso-efectoras de otredad, ética, límite y moral}

La existencia humana se da en un contexto relacional de conversaciones; por lo tanto, el vivir cotidiano lo constituye el lenguaje "como fenómeno biológico relacional en un coexistir en interacciones recurrentes bajo la forma de un fluir recursivo de coordinaciones de coordinaciones conductuales consensuales" (Maturana, 1993, p. 9); esto es "lo que distinguimos cuando distinguimos emociones en nosotros y en otros animales son dominios de acciones a otro en un continuo emocionar que se entrelaza con nuestro lenguajear; este entrelazamiento entre el lenguajear y el emocionar lo llamaremos conversar y mantenemos que todo el vivir humano se da en redes de conversaciones" (Maturana, 1993, p. 9).

En tal sentido, la descendencia humana ha conservado en redes de conversaciones lo que hoy se conoce como ética en cuanto cuerpo de conocimientos que en un momento dado permite distinguir lo que es "bueno" y "malo" y de allí toman decisiones y realizan juicios de valor que podrían ser erróneas, injustas y/o justas. Po ejemplo: ¿les pertenece al ser vivo humano juzgar que le hace bien o mal a alguien? De hecho, sí; pero, se sabe que hay drogas que hacen daño a las personas; ahora ¿cuáles drogas?, ¿las que se le inyectan a un paciente de cáncer para disminuir el dolor o las cocaínas que consume el adicto? Culturalmente se declara que no son dañinas las primeras y sí lo son las segundas; ahora bien, a un joven que cayó en el consumo de cocaína ¿se le juzgaría como mal o buen muchacho? Desde lo que se distingue por malo como el consumir ese tipo de drogas, sí.

Sin embargo, ¿qué pasa con el respeto hacia esta persona? No se trata de aceptar que los hombres, mujeres, niños o niñas ingieran un producto nocivo, sino saber qué 
pasó en la historia de la persona y escucharlo (Otredad); de seguro, esto llevaría a otros modos de intervenir que no sean el rechazo, porque el muchacho no es naturalmente malo, sino que la condición de "bueno" o "malo" se ha construido en la cultura. Cuando se llegue al consenso de la ética como acción de hacer el bien y se encarne en la red de conversaciones, las emociones de los seres humanos serán dadas desde la relación del amor, el escuchar, respetar, perdonar y convivir como legítimos otros que son.

En este orden de ideas, las conversaciones sobre otredad, algunos autores lo plantean como alteridad: "(la existencia del otro) siempre complica la existencia del yo, por eso la forma más adecuada de hablar de ella es el nosotros. Seguimos siendo nosotros en la oposición, en la exclusión mutua, en la guerra" (Ruiz, 2007, p. 10). No obstante, Labrador (2018) considera que el "nosotros" en la otredad mediante el proceso autoconsciente de las personas, éstas miran las conversaciones que conservan generando cambiamos en el hacer y las emociones en las que se mueven, donde cada uno no teme perder su legitimidad al aceptar la diversidad del otro $y$, es así como en la dinámica relacional se es un nos-otros, es decir, cada uno siendo ser único en coherencia con el respeto a sí mismo y lo multiverso del otro, la otra, lo otro. Respecto a la ética hasta ahora se ha manejado como la doctrina o cuerpo de teorías que permiten al hombre distinguir entre lo "bueno" y lo "malo" como referente para tomar decisiones, como observador que es, lo que permite intervenir en una cultura determinada y por ende controlarla, es decir, expresarle a otros lo que deben o no deben hacer; entonces la moral entra como una forma de reglas o leyes que "deben ser cumplidas" por los miembros de una comunidad, donde se originan unos valores morales, religiosos, profesionales, entre otros.

Por otro lado, el límite tomaría la cara de fin de una meta y después de alcanzarla se puede creer que se ha logrado todo. Tomando en cuenta esto cabe preguntarse: ¿este "deber ser" tendrá que ver con el "ser"?, ¿cómo saber si la norma impuesta es aceptada por el otro? Y ¿hasta qué punto tiene que ver con los requerimientos de la otra persona? Existen tantas reglas dadas a los jóvenes, niños, niñas y adultos no sólo en el campo laboral, escolar, familiar, sino inclusive en lo personal, sin tomar en cuenta, muchas veces, si están de acuerdo o no con lo impuesto, debido a que se 
cuenta con una serie de teorías y leyes que permiten inducir a un grupo de personas, desde una percepción del conocimiento en cuanto a razón absoluta, y no desde la indigencia de ser-en-el límite donde radica la grandeza de la condición humana. Parece que el único modo de conocer es el de los extremos: Bueno/malo, aplazado/eximido, concepciones que se manifiestan en la comunicación, respondiendo ante emociones absolutistas en función de lo que a través del tiempo se ha conocido y mantenido.

De esta forma, se proyecta un comportamiento controlador, violento, ante los otros, y los jóvenes aprenden a existir en este ambiente porque es lo que configuran de la conducta de los adultos. Resulta de vital importancia que el docente se pregunte ¿qué niño quiere?, ¿cuál es la educación que quiere?, ¿qué país es quiere forjar?

La Educación como mediador de una formación ética, podría considerar establecer la inclusión de nuevos términos en el lenguaje de los alumnos, docentes, padres y representantes, tomando en cuenta:

a) Una ética social, donde se comprenda que nuestra condición humana implica sentir, mostrar afecto.

b) Encarnar la moral social como la construcción a través de la experiencia de la historia de vida de cada hombre, quien, según lo que haya construido, hará una distinción-como el observador que es-de lo bueno, lo malo, lo más o menos, y para que las creencias de sí mismo y del mundo involucren la idea de un ser sistémico no aislado, necesita aprender que una moral social regula la unión de los seres en comunidad. Una norma moral, no donde se cumpla la ley sin estudiar sus consecuencias, sino donde se respete a la persona sin imposición de cumplimiento por temor al castigo, donde se aprenda a respetar y no a obrar por conveniencia.

c) El que sean autónomos y libres cuando hacen por voluntad lo que quieren sin atentar contra el bien común.

d) Educar en los valores de la libertad, convivencia, desinterés de hacer el mal, toma de decisiones que proyecte el potencial humano de los hombres, sentido del contexto, respeto y en especial para: 
e) Asumir la responsabilidad de nuestras elecciones y las consecuencias que de las mismas se derivan.

Para ello, se requiere cambiar la red de conversaciones empezando por lo que es, desde Trías (2000), la ética, haciendo mención de hacer el bien y, por supuesto, una moral que enseñe reglas donde el hombre se aleje de realizar actos que hagan daño al otro; así como, reconocer que el límite está en que los seres son finitos por naturaleza y que en la imperfección se encuentra lo "perfecto". Lo cual presupone una relación donde se dignifica la persona humana tal como proyectan Aldana Zavala \& Isea (2018), al gestionar una interrelación humana basada en el reconocimiento del otro como sujeto activo y protagónico del quehacer histórico social.

\section{ÉTICA, LÍMITE Y MORAL: OTRO MODO DE CONVERSAR}

Hasta este momento se ha definido a la ética como un conjunto de teorías que le permiten al ser humano distinguir lo que es "bueno" o "malo", al límite como "confín" y a la moral como el cuerpo de leyes o reglas que rigen la conducta del hombre en la sociedad. Sin embargo, reestructurar el lenguaje en la red de conversaciones y con ello el rumbo que se ha llevado, ocurre pasando por otros caminos de conocimiento, como el de Trías (2000), quien considera la ética como un hacer el bien al otro y a la moral como la enseñanza de reglas que alejen al ser humano del mal y lo acerquen más al bien común; donde niño, niña, hombre, mujer, adulto contemporáneo tengan respeto y se acepten a sí mismos para poder respetar y aceptar a los demás.

El hombre está en un diálogo entre la razón y sus sombras; la primera, representaría lo que es educable, lo encontrado en el mundo a lo largo de la experiencia; los segundos, estarían relacionados con el ser, el que no tiene concepto, ni explicación, es que es. Trías (2000), llama a ese Filosofía del límite, y al concepto de razón o de inteligencia racional, que a esa filosofía del límite corresponde, la denominó razón fronteriza. Ésta última encierra lo relativo al conocimiento, lo cognitivo, el cómo hacer las cosas y qué saber de las mismas, que cuando el hombre cree que lo ha hecho todo, que lo sabe todo, entonces empieza a alejarse de su ser en el límite y deja de avanzar en lo espiritual y corpóreo. 
El límite como expresa Ricardo (2000), es la finitud, la contingencia, la relatividad, la no eternidad de la realidad; el límite está dentro del ser y no es algo externo. Las personas están dotadas de una estructura ontológica que a su vez es dinámica y genera su misma estructura sobre la experiencia; la riqueza del hombre está en su indigencia ya que está en una búsqueda constante de su función en la vida, la reflexión de sus acciones y la construcción de un mejor vivir.

Se le habla al educando del futuro; aquel crece pensando en lo que hará, qué estudiará y cómo lo logrará, insertándose en la idea del más allá y no del aquí y ahora, dejando de lado la plenitud de la experiencia vivida día a día y sembrando así la visión del producto. Muchos son los esfuerzos del profesor para educar al niño y niña como hombre y mujer de "bien", ahora ¿dónde entra la formación humana?, ¿cómo formar lo humano?, ¿cómo saber si el ser un hombre y mujer de "bien" es para uno la misma distinción que para el otro? Si las conversaciones son de índole académica, y se le dice al joven que es "buen alumno" en la medida en que el promedio de notas está en el nivel de eximido, entonces entra la idea de que todo se mide.

Por otra parte, está el muchacho y la muchacha con dos, tres y hasta nueve materias aplazadas, a quienes se les adjudica que siempre está mal lo que son, o que no saben, ni harán nunca nada, basados en la creencia de que es inteligente el alumno de mejor promedio de notas, dando espacio a la inconformidad, vergüenza y una pobre estima. Es decir, se busca un cambio no en el hacer del alumno, sino en el ser, tejiendo una red de conversaciones concerniente a: "PROHIBIDO EQUIVOCARSE", otorgándole el poder a la razón como lo absoluto, dando paso a que el niño y niña pierdan la aceptación de sus límites, y con ello el que no se reconozcan como seres únicos; en consecuencia, el otro es negado como un legítimo otro, emergiendo en las relaciones la agresión, obviando el amor y el perdón como condición humana. Así, se está formando niños y niñas inseguros de sí mismos que se rinden a las drogas, el alcohol y la violencia.

La tarea educativa, se apoya en la forma en que el docente se autoacepta y mira al otro como ser legítimo en el convivir, coexistiendo en el espacio relacional que le corresponde y no en función de un futuro que sólo emerge del hoy. Hay que aceptar ser en el límite. 


\section{Hacia la construcción de una eticidad de la otredad: relaciones colaborativas en nuevas redes de conversaciones}

Santana (2000), explica que la eticidad es el proceso de construcción de valores comunes en la comunicación. Ante todo es importante estar claro qué son los valores, para Santana (2000) ellos siempre han existido y no se puede definir valores como tal, en vista de que éstos en sí no existen, sino elementos a los cuales las personas se adhieren. Ahora bien, ¿qué elementos se quieren adherir en el proceso de construcción de una eticidad de la otredad y su importancia en el cambio de conversaciones? Para Senge, Dávila y Maturana (2011) implica una gerencia éticosocial que considera los siguientes aspectos y/o elementos:

-Coordinación de personas desde una postura no-jerárquica.

-Hacer ético (asumir las consecuencias de las decisiones tomadas, hacer bien).

-Propósitos co-inspirados y responsabilidades compartidas.

-Realización de un proyecto común, visión compartida.

-Sentires, emociones de respeto y relaciones de colaboración.

-La Inteligencia y la creatividad se expande.

-Conversaciones de auto respeto y respeto al otro. Acciones que involucra a los actores como persona.

\section{MARCO METODOLÓGICO}

Diseño de la investigación: con el propósito de orientar las estrategias requeridas para alcanzar los objetivos del estudio, el plan que se llevó a cabo fue más libre que estructurado, aunque tuvo su estructuración en la deriva natural de la investigación, en el sentido de que, el enfoque vivencial se encaminó en una metódica fenomenológica en una corriente relacional- teórica-reflexiva, ya que los docentes involucrados en el estudio exploraron, describieron y comprendieron desde las experiencias narradas el fenómeno de la otredad, y los cambios en las acciones al desmontar las redes de conversaciones sobre ética, límite y moral hacia una eticidad del proyecto común en relaciones colaborativas. Se consideró como variable 
independiente la Otredad y como variable dependiente los Cambios de conversación.

La población, según Hernández, Fernández y Baptista (2014), es "el conjunto de todos los casos que concuerdan con determinadas especificaciones" (p. 174). En el caso particular de esta investigación la constituyeron los docentes del Instituto Indígena "San Antonio de Aremasain" de Riohacha-Colombia. La muestra, según el mismo autor, "se determina durante o después de la inmersión inicial. Se puede ajustar en cualquier momento del estudio. No es probabilística. No busca generalizar resultados" (p.387). Para el caso de esta investigación, los actores involucrados en el estudio fueron 65 docentes del Instituto Indígena "San Antonio de Aremasain" de Riohacha-Colombia.

La técnica utilizada en la realización del vivir-convivir durante el proceso de investigación, fue la observación en situaciones de conflicto intraindividual e intergrupal, mediante un papel de escucha activa, utilizando todos los sentidos, así como una reflexión permanente. Además, se diseñó un taller que exploró las distinciones que los docente manejan en relación a la ética, la moral y el límite con base a la otredad, las normas morales que existen en la escuela y las repercusiones que tienen al momento de tomar decisiones el docente frente a una situación del contexto, la toma de consciencia hacia los cambios en la emoción, las acciones y conversaciones sobre ética, límite y moral.

Se utilizaron dos instrumentos para medir la variable independiente otredad; el primero, se tituló "el espejo", el cual consistió en la toma de consciencia de conversaciones, emociones y conductas en las experiencias tanto positivas como negativas en el contexto laborar. El segundo, titulado "sociodrama" con el fin de concientizar las conversaciones sobre ética, límite y moral que intervienen en la dinámica relacional colaborativa y no colaborativa. Lo concerniente a la variable dependiente, Cambios de conversación: también se utilizaron dos instrumentos. El primero, Mapa conceptual, en la cual se trabajó la reestructuración en el lenguaje acerca de la Ética, Límite, Moral y otredad. Mapa mental, donde los docentes definieron un proyecto común co-inspirativo, de responsabilidades compartidas de respeto y colaboración. 
Par el análisis de los datos, posterior a la observación grupal y las experiencias descritas por los docentes se organizaron en unidades de observación, las cuales generaron las categorías, éstas las subcategorías con el nivel de frecuencia en que aparecen en las redes de conversaciones de los participantes, dando pautas para identificar cómo fue la experiencia en el contexto educativo.

Unidad de Análisis de Otredad y cambios de conversación. Figura 1

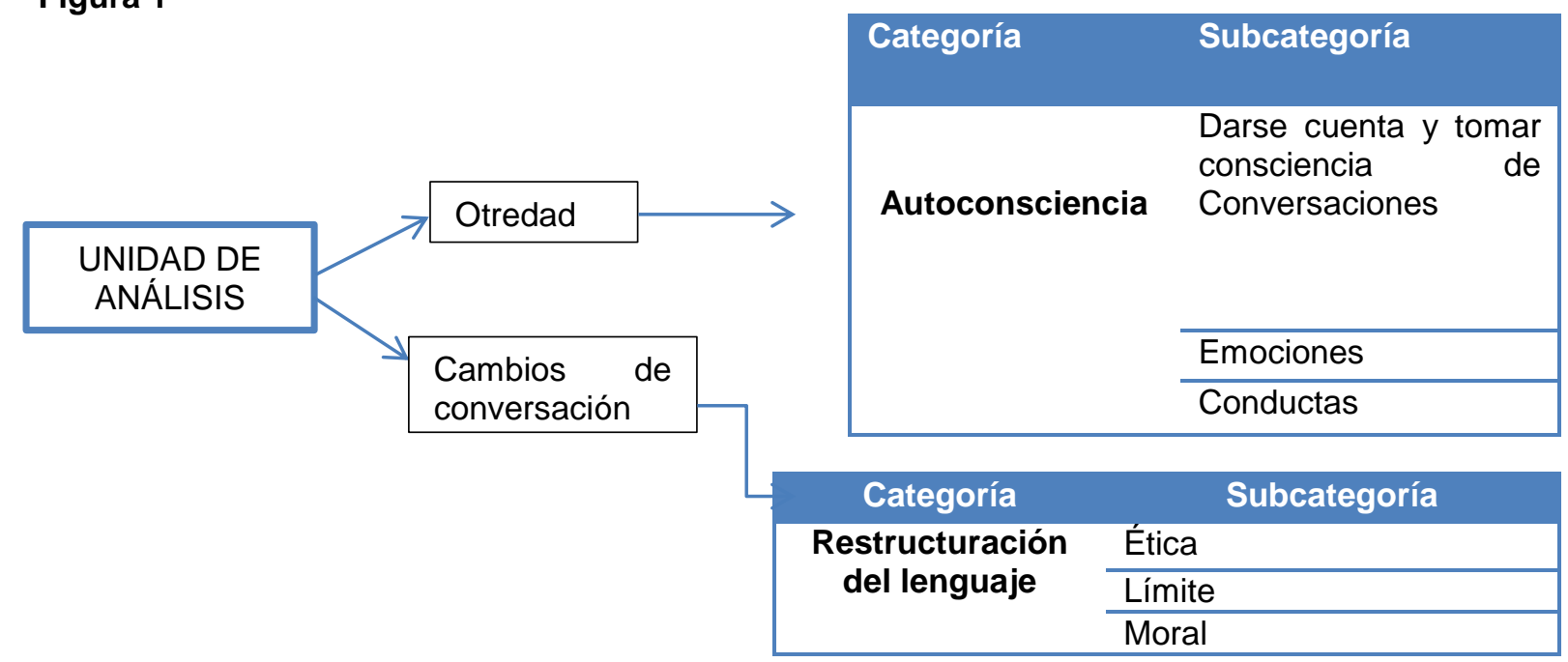

Fuente: elaboración propia, (2019), a partir de Hernández et. al, (2014).

En la dinámica relacional desde el vivir-convivir de los docentes, desde sus experiencias, aportaron configuraciones que en la interacción con los compañeros/compañeras trajeron a sus manos aspectos o elementos significativos para comprender el fenómeno de la otredad, en especial, la importancia en el cambio de conversaciones sobre ética, límite y moral ante la diversidad de pensamiento. Elementos que emergieron del sentir íntimo, los haceres y emociones, ejemplificados en las circunstancias presentadas en la deriva natural del presente cambiante continuo que les ha tocado vivir y que les llevó a construir un proyecto común de relaciones colaborativas. 
Por lo que, el procedimiento de los datos se analizó: 1. con base a la opinión de Hernández, Fernández y Baptista (2014) respecto a que en la recolección de datos "ocurre en los ambientes naturales y cotidianos de los participantes o unidades de análisis. En el caso de seres humanos, en su vida diaria: cómo hablan, en qué creen, qué sienten, cómo piensan, cómo interactúan, etc." (p. 397). Esto es, principalmente lo que pasó en cada encuentro, donde el principal protagonista, se enfocó en los docentes y 2. De significados: "son los referentes lingüísticos que utilizan los actores humanos para aludir a la vida social como definiciones, ideologías o estereotipos" (Hernández et al. 2014, p. 397). Acá emergieron las configuraciones o estilos de vida sobre ética, moral, límite, con base en la otredad. Lo que llevó a la toma de consciencia de las conversaciones que conservan las acciones o comportamientos de negación al otro por diferir en el quehacer educativo, y las emociones que la subyacen.

\section{RESULTADOS}

Una vez aplicado el taller que llevó por nombre: "Otredad, Ética, límite y Moral. Otro modo de conversar" a 65 docentes del Internado Indígena "San Antonio de Aremasain de Riohacha, Colombia, se procedió a realizar el tratamiento correspondiente para el análisis de lo acontecido en el taller, por cuanto la información que arrojó fue la que indicó las conclusiones a las cuales llega la investigación, por cuanto mostrará las conversaciones que posee el profesorado acerca de la ética, el límite y la moral cómo intervienen ante casos de relaciones colaborativas y no colaborativas de la institución donde laboran.

En la toma de consciencia de conversaciones, emociones y conductas en las experiencias tanto positivas como negativas en el contexto laborar, se halló que los docentes en circunstancia de relaciones armónicas el 100\% se mueve en la emoción de alegría, expresando en las relaciones entre compañeros palabras de afecto, presentando conductas de cooperación y de amistad. Mientras que en circunstancias de conflicto ante la diferencia de pensamiento referente al trabajo en el contexto laboral, un $76,9 \%$ se mueve en la emoción de la rabia, con conversaciones en tono alto y palabras que connotan ofensa al otro, sosteniendo conductas de violencia verbal, mientras que un $23,3 \%$ se mueve en la emoción de tristeza, con 
conversaciones que connotan ruptura en la relación, con una conducta de alejamiento al otro. Tomando consciencia de las distinciones que configuran en la dinámica relacional consigo mismo y el otro desde el emocionar en que se mueven, el actuar y las conversaciones que conservan.

De modo que, lo que distinguimos cuando "distinguimos emociones en nosotros y en otros animales son dominios de acciones a otro en un continuo emocionar que se entrelaza con nuestro lenguajear; este entrelazamiento entre el lenguajear y el emocionar lo llamaremos conversar y mantenemos que todo el vivir humano se da en redes de conversaciones" (Maturana, 1993, p. 9). Lo que dio a paso a las distinciones que manejan por ética, límites y moral.

Mediante el sociodrama, los docentes concientizaron expresando distintos puntos de vista acerca de la ética, puesto que para el 3, 3\% "son principios", 4,6\% consideraron "es el compromiso hacia la profesión", $6,1 \%$ es "el deber ser" y $86 \%$ manifestaron que se "debe a seres que viven en sociedad". En cuanto al concepto de límite 7,6\% expusieron que "nos hace libre" y 92,4\% los lleva "al respeto social". La moral 18,4\% le adjudicaron lo cultural, donde, "según como sean las costumbres del país donde se viva se implementan una serie de principios, leyes, normas o reglas que hacen a una persona actuar de la manera que ésta crea conveniente deba ser" y, 8,6\% lo consideraron "creencias que el hombre tiene y es lo que llevan o mueve a una acción". Se puede dilucidar que las definiciones arriba señaladas presentan una mezcla entre lo que debe hacerse y hacer el bien; es como si desde el divorcio entre el deber ser con el ser hubiese una posible reconciliación, y no está lejos ya que se busca una ética inclinada a la acción, esto llevó a los docentes a reflexionar ¿dónde estamos ubicados?, desde el ¿deber ser? O ¿el ser? Verbalizando los profesores que se ubican en el deber ser en cuanto, desde el observador que cada uno es, creen que se deben hacer las cosas, identificando que los elementos donde se ubica su quehacer educativo es un liderazgo jerárquico-no ético.

Dando paso por medio del mapa conceptual, la reestructuración en el lenguaje acerca de la Ética, Límite, Moral y otredad. Manejando el $100 \%$ en sus red de conversaciones que la ética, como lo manifiesta Trías (2000), y Peter (2000) es hacer el bien común desde el habitad, la moral como las reglas que deben enseñarse en función de hacer 
el bien y alejarse de acciones que hagan mal a otros, tomando de Santana (2000) la construcción de una eticidad en la aceptación entre ellos como seres diversos y el límite como la finitud del ser humano, el reconocimiento de nuestra mortalidad y la riqueza desde la indigencia. El $100 \%$ de los docentes consensuaron en la verbalización que el amor es "ver al otro diferente a uno como alguien de quien se aprende, no como un adversario, sino como un ser único que vive en convivencia". De este cúmulo de reflexiones, el $100 \%$ de los educadores construyeron su eticidad, mediante un mapa mental en conjunto, donde definieron un proyecto común coinspirativo, de responsabilidades compartidas de respeto y colaboración quedando así:

-Respetar la personalidad del compañero de trabajo, reconociendo que las personas son diferentes entre sí, aprendiendo de aquel y dejarlo de ver como un adversario.

-Ser auténticos en lo que se enseña y tener una conducta coherente con el sentir, hacer, la emoción y conversación.

-Realizar lecturas de crecimiento personal.

-Consensuar en las decisiones que llevan a corregir en pro del bienestar de todos y todas.

-Dejar los intereses personales.

-Espíritu de servicio.

-Ser un docente religioso: profesar el ser cristiano.

\section{CONCLUSIONES}

a) El proceso autoconsciente en las conversaciones, emociones y conductas generan cambios en los sentires, haceres y emociones en las personas, llevándolos, desde el espacio de reflexión que la autoconsciencia abre, a desmontar las distinciones que conservan relaciones no colaborativas por relaciones colaborativas.

b) La comprensión de la ética como cuerpo de teorías que permite distinguir entre lo que es bueno o malo no es el único modo de conocer la realidad, ni intervenirla, sino también una ética desde hacer el bien común, donde las 
reglas a impartir sean en beneficio al otro como un ser humano que es igual en su organización: ser vivo humano.

c) El hombre es un ser finito, mortal, cuando acepta su ser en el límite; descubre que la riqueza está en su indigencia, es decir, la búsqueda continua de ser- en el mundo.

d) La moral dada desde el bienestar del otro construye la moral social, en la cual se tejen redes de conversaciones de la convivencia, el amor, el perdón y la paz.

e) La emoción del amor está en aceptar lo multiverso del otro como aprendizaje y no como un enemigo.

f) La reestructuración en el lenguaje acerca de la ética, la moral, el límite y la eticidad con base en la otredad, lleva a un cambio de comportamiento en quienes lo viven, llevándolos a hacer el bien común.

A manera de reflexión final se presenta esta sugerencia conclusiva: la vida: ser en la experiencia, mueve al hombre en si indigencia, la cual lo empuja a buscar su creatividad, lo religioso, las interacciones sociales; así, construir la historia personal, en una red de relaciones donde desde la comunicación, éste necesita narrar la imagen que tiene de sí y recibir la narración de los otros; esto hace que el ser humano vaya formando un sistema de valores que le permita ver e interpretar la realidad, en consecuencia, actuar ante el quehacer cotidiano. García, García \& Isea (2017), comentar la necesidad de fomentar la ética en la formación docente como un elemento generador de ciudadanía para la vida.

La educación entra como mediador, para guiar, generar distinciones que la persona formule en cualquier dimensión de la realidad. Por ello, se invita a realizar este tipo de actividades llevadas a cabo en este estudio, en todas las Instituciones de Educación, en especial en las universitarias y con las familias. Estamos centrados más en lo cognitivo que en el saber hacer y saber convivir, se hace indispensable cambiar los haceres que alejan del bien común por aquellos que lo acerquen. 


\section{REFERENCIAS CONSULTADAS}

1. Aldana Zavala, J., \& Isea, J. (2018). Derechos Humanos y Dignidad Humana. IUSTITIA SOCIALIS, 3(4), 8-23. Recuperado de http://fundacionkoinonia.com.ve/ojs/index.php/lustitia Socialis/article/view/119 $\underline{101}$

2. García., L., García, J., \& Isea, J. (2018). LA FUNCIÓN ÉTICA Y SOCIAL DEL GERENTE EDUCATIVO. Revista Arbitrada Interdisciplinaria Koinonía, 2(3), 8091. Recuperado http://fundacionkoinonia.com.ve/ojs/index.php/revistakoinonia/article/view/53/4 $\underline{0}$

3. González, J. (1996). El Ethos, destino del hombre. Fondo de Cultura Económica. México.

4. Hernández, R., Fernández, C. y Baptista, P. (2014). Metodología de la Investigación (6⿳⺈冂䒑 ed.). México D.F, México: McGRAW-HILL.

5. Maturana, H. y Dávila, X. (2015). El árbol del vivir. Santiago de Chile: MVP.

6. Maturana, H. (1993). Amor y juego: fundamentos olvidados de lo humano. Instituto de Terapia Cognitiva. Santiago de Chile.

7. Peter, R. (1997). Una terapia para la persona humana. Universidad Autónoma de México.

8. Real Academia Española. (2014. Ética. En Diccionario de la lengua española (23 a ed.). Consultado en https://dle.rae.es/?id=H3y8lij|H3yayOR

9. Real Academia Española. (2014). Límite. En Diccionario de la lengua española (23 a ed.). Consultado en https://dle.rae.es/?id=NKZgeLY

10. Real Academia Española. (2014). Moral. En Diccionario de la lengua española (23 a ed.). Consultado en https://dle.rae.es/?id=Pm2wZfs|Pm4ASgl

11. Ruiz-DelaPresa, J. (2007). Alteridad: Un recorrido filosófico. Repositorio Institucional del ITESO, 1-184. Recuperado de file:///C:/Users/User/Documents/Alteridadleer.pdf

12. Santana, L. (2000). Ética y Docencia. FEDUPEL. Caracas.

13. Senge, P., Maturana, H. y Dávila, X. (2011). Organizaciones Socio-etico sustentable: un camino hacia un futuro distinto. Visiones telefónicas, (11), 1-8.

14. Trías, E. (2000). Ética y condición humana. Ediciones Península. Barcelona. 
15. Varela, R. (1996). Ética y acción. DOLMEN. Santiago de Chile.

\section{REFERENCES CONSULTED}

1. Aldana Zavala, J., \& Isea, J. (2018). Human Rights and Human Dignity. IUSTITIA SOCIALIS, 3 (4), 8-23. Retrieved from http://fundacionkoinonia.com.ve/ojs/index.php/lustitia_Socialis/article/view/119 $/ 101$

2. García., L., García, J., \& Isea, J. (2018). THE ETHICAL AND SOCIAL FUNCTION OF THE EDUCATIONAL MANAGER. Interdisciplinary Arbitrated Review Koinonía, 2 (3), 80-91. Recovered from http://fundacionkoinonia.com.ve/ojs/index.php/revistakoinonia/article/view/53/4 0

3. González, J. (1996). The Ethos, destiny of man. Fund of Economic Culture. Mexico.

4. Hernández, R., Fernández, C. and Baptista, P. (2014). Research Methodology (6th ed.). Mexico D.F, Mexico: McGRAW-HILL.

5. Maturana, H. and Dávila, X. (2015). The tree of living. Santiago, Chile: MVP.

6. Maturana, H. (1993). Love and play: forgotten fundamentals of the human. Institute of Cognitive Therapy. Santiago of Chile.

7. Peter, R. (1997). A therapy for the human person. Autonomous University of Mexico.

8. Royal Spanish Academy. (2014. Ethics. In Dictionary of the Spanish language (23 a ed.). Consulted in https://dle.rae.es/?id=H3y8ljj|H3yay0R

9. Royal Spanish Academy. (2014). Limit. In Dictionary of the Spanish language (23 a ed.). Retrieved from https://dle.rae.es/?id=NKZgeLY

10. Royal Spanish Academy. (2014). Moral. In Dictionary of the Spanish language (23 a ed.). Retrieved from https://dle.rae.es/?id=Pm2wZfs|Pm4ASgl

11. Ruiz-DelaPresa, J. (2007). Alterity: A philosophical journey. ITESO Institutional Repository, 1-184. Recovered from file: I/I C: /Users/User/Documents/Alteridadleer.pdf

12. Santana, L. (2000). Ethics and Teaching. FEDUPEL Caracas. 
13. Senge, P., Maturana, H. and Dávila, X. (2011). Socio-ethical sustainable organizations: a path towards a different future. Telephone visions, (11), 1-8.

14. Trías, E. (2000). Ethics and human condition. Peninsula editions. Barcelona.

15. Varela, R. (1996). Ethics and action. DOLMEN. Santiago of Chile.

C2019 por los autores. Este artículo es de acceso abierto y distribuido según los términos y condiciones de la licencia Creative Commons Atribución-NoComercial-Compartirlgual 4.0 Internacional (CC BY-NC-SA 4.0)

(https://creativecommons.org/licenses/by-nc-sa/4.0/ 